\title{
THE STATUS OF NURSING RESEARCH IN THE REPUBLIC OF SOUTH AFRICA: PAST AND PRESENT PERSPECTIVES
}

\author{
H.I.L. Brink
}

Paper dellvered at the 10th

Anniversary Conference on Research In Nursing Education at the Hyatt

Regency, Embarcadero Centre, San Francisco, Callfornia - 12-14 February 1992.

\section{INTRODUCTION}

Research never develops in a vacuum, hence a discussion of the status of research in a country cannot be limited to a single point of time, nor can it be properly understood without reference to issues and events which have influenced its past and present status. The purpose of this paper is to present an overview of the development of nursing research in South Africa and of the current nursing research situation. Comment is made on current trends in nursing research, the nature and status of nursing research as well as specific issues and events that have affected development and current stanus of nursing research in South Africa. The development and nature of nursing research was traced through two major sources - the National Nursing Research Journal "Curationis", and the National Nursing Research Register - a publication of the South African Nursing Association, which provides abstracts of nursing research completed and underway in this country. This information was supplemented by several research publications and papers.

\section{OVERVIEW OF THE \\ DEVELOPMENT OF NURSING RESEARCH}

Nursing research in South Africa is relatively young. Depending on how broadly or specifically one defines the term nursing research and more specifically the purpose of nursing research, different answers will emerge as to its age. Most nurses would agree that the comerstone for the development of nursing research in South Africa was laid forty years ago in 1951, when the first nurse in South Africa to obtain an earned masters degree did so in Sociology. In the same year (1951) the President of the South African Nursing Council clinched an argument for the need for nursing research by publicly stating
"Nursing progress without research is a house without foundation" (Searle, 1990). As nursing degrees were not available at South African universities at that stage steps were taken to include a research component in the post-registration diploma course in nursing administration. Students in this course were required to complete elementary descriptive studies on problem areas in their field under the leadership of Charlotte Searle, the first nurse who had obtained her masters degree. These studies though elementary and practical were presented in a systematic and organised manner. They augmented the first masters study and made a notable contribution to the reform of nursing service and education (Searle, 1990). Unfortunately, no documented evidence is available that these early post-registration students continued with independent research after completion of their studies. On the whole research activity in the practice area was negligible and consisted largely of co-operation with and/or assistance to members of other disciplines.

Several nurse leaders have discounted this early period in the development of nursing research and have identified 1969 as the year in which nursing research in South Africa originated (Uys 1982, Uys 1991). This was the year in which a group of six nurses successfully completed the first masters programme in nursing in South Africa launched at the University of Pretoria in 1967 (Uys, 1982).

The initiation of post-graduate nursing in South Africa certainly constituted a most important impetus in the development and progress of nursing research in the country. During the 1970s growth was gradual but pace increased during the eighties and certain highlights were achieved during this decade. Evidence of the growth of nursing research activity in South Africa during the period 1951-1990 is reflected in Table 1.

As depicted in Table 1 a total of 256 research studies were completed over a span of 33 years from 1951 to 1984 , giving an average of 7,7 studies annually, while a six to thirteen fold increase in studies occurred annually over the past six years (1985 to 1990). Doctoral studies more than tripled during the eighties while masters studies more than doubled and basic degree studies increased by almost 700 percent over the last decade. Projects done as a requirement for diploma studies and independent projects grew at a much slower rate. By 1990 some 645 completed studies

\begin{tabular}{|c|c|c|c|c|c|c|}
\hline YEAR & DOCTOAAL & MASTERS & $\begin{array}{c}\text { BASIC } \\
\text { DEGREES }\end{array}$ & $\begin{array}{c}\text { INDEPEN } \\
\text { DENT }\end{array}$ & DIPLOMA & TOTAL \\
\hline 1990 & 5 & 22 & 17 & 14 & 16 & 74 \\
\hline 1989 & 6 & 11 & 9 & 1 & 10 & 37 \\
\hline 1988 & 7 & 51 & 14 & 7 & 20 & 99 \\
\hline 1987 & 5 & 22 & 2 & 13 & 3 & 45 \\
\hline 1986 & 10 & 25 & 16 & 22 & 11 & 84 \\
\hline 1985 & 2 & 18 & 9 & 13 & 8 & 50 \\
\hline $\begin{array}{l}1951^{\circ} \\
\text { to } \\
1984\end{array}$ & 14 & 113 & 10 & 42 & 77 & 256 \\
\hline TOTAL & 48 & 262 & 77 & 112 & 145 & 645 \\
\hline
\end{tabular}


TABLE 2: Classification of post-graduate nursing studles completed during the periods 1969 to 1979 and 1980 to 1990 according to field of study

\begin{tabular}{|c|c|c|}
\hline FIELD OF STUDY & $\begin{array}{r}N=55 \\
\% \text { STUDIES } \\
1968-1979\end{array}$ & $\begin{array}{r}N=248 \\
\% \text { STUDIES } \\
1980-1990\end{array}$ \\
\hline General Nursing & 1,8 & 1,7 \\
\hline Community Health & 5,4 & 21,4 \\
\hline Psychiatry & 7,3 & 14,4 \\
\hline Midwitery & 7,3 & 4,2 \\
\hline Intensive/Clinical Specialities & 30,9 & 3,3 \\
\hline Administration & 16,4 & 23,1 \\
\hline Education & 20,0 & 21,4 \\
\hline Philosophy & 3,6 & 4,4 \\
\hline History & 7,3 & 4,4 \\
\hline Other & - & 1,7 \\
\hline
\end{tabular}

(Dertved Irom Uys 1982, 31)

were available of which 389 had been produced during the past six years. The decade of the eighties can thus rightfully be called the most productive period with regard to nursing research in South African history. Of the total studies completed during the past six years, doctoral theses made up $8,9 \%$, masters studies $38,3 \%$, studies for basic degrees $17,3 \%$, diploma studies $17,5 \%$ and independent projects $17,9 \%$. An increase in the number of nurses progressing to masters and doctoral level is welcomed. Unfortunately, judging from the very low increase in independent projects, it seems that most nurses prepared at post-graduate level tend to regard their research degree as an end, rather than a means to an end.

\section{THE NATURE OF NURSING RESEARCH}

To establish the nature of South African nursing research all abstracts on post-graduate studies completed during 1980 to 1990 were reviewed, coded and classified, according to the same criteria used in a study on the nature of post-graduate nursing research completed during the period 1969 to 1979 (Uys, 1982).
Classification was done according to area or field of nursing, design and purpose of the study. Tables 2,3 and 4 depict these findings.

\section{A reas or fields of study}

The most significant differences among study areas during the decade of the seventies and that of the eighties are the decrease in intensive and clinical specialty areas from $30,9 \%$ to 3,3 $\%$ and the increase in Community Health studies from 5,4 to 21,4 percent. The latter is welcome, particularly because of the important contribution community nursing can make in developing areas of South Africa. The dearth of clinical studies in post-graduate work gives rise to concern. Though clinical studies comprise almost 49 percent of all research studies documented in South Africa, the bulk of these studies are very elementary studies done as group projects by diploma and basic degree students and were not included in this study.

A further analysis of the studies under each of these areas indicated that the majority of studies in each of the areas (a total of $44 \%$ ) are caregiver centered (role and function - characteristics and perceptions) while only one single study is patient-centered. Just over seven percent deal with standards and quality of care and another seven percent with curriculum and teaching strategies. Ten percent deal with psycho-social aspects or interpersonal relations, while only one study was found on theory development and two on transcultural aspects of nursing.

\section{Design of study}

As reflected in Table 3 the survey approach dominates the scene. Over 84 percent of students used this approach for their studies during the 1980 s.

\section{Purpose of the study}

No dramatic changes occurred during the decade of the eighties as far as the purpose of the research studies is concerned. As during the decade of the seventies, most of students in the eighties presented descriptive level one studies. A small beginning has been made in theory testing and theory development which is encouraging.

\section{CURRENT STATUS OF NURSING RESEARCH}

An extensive review and evaluation of recent post-graduate studies (1980 to 1990) available in the libraries of the South African Nursing Association and the University of South Africa was done to obtain more information on the nature of the actual studies. A total of eighty studies was reviewed which constitutes $32 \%$ of the total number of masters and doctoral studies completed during the period under study. Care was taken to include studies from each of the classified areas. Evaluation criteria proposed by Polit and Hungler (1991) were used.

Some studies, though very few, could be classified as substantive, innovative and methodologically sound. On the whole the following picture emerged:
TABLE: 3 Classification of post-graduate nursing studies completed during the periods 1969 to 1979 and 1980 to 1990 according to design

$\begin{array}{lrr} & \text { N }=55 & \text { N }=248 \\ & \text { \% STUDIES } & \text { \% STUDIES } \\ & 1969-1979 & 1980-1990 \\ \text { Experimental } & 3,7 & 0,4 \\ \text { Quasi-experimental } & 3,7 & 0,8 \\ \text { Ex post facto correlation } & 1,9 & - \\ \text { Survey } & 66,7 & 84,4 \\ \text { Philosophical } & 3,7 & 4,4 \\ \text { Historical } & 7,4 & 4,4 \\ \text { Literature studies } & 13,0 & 2,4 \\ \text { Evaluative } & - & 2,0 \\ \text { Qualitative } & - & 1,2\end{array}$

TABLE 4. Classification of post-graduate nursing studies completed during the periods 1969 to 1979 and 1980 to 1990 according to purpose

$\begin{array}{lrr} & \begin{array}{r}\text { N }=55 \\ \text { \% STUDIES }\end{array} & \begin{array}{r}\text { N }=248 \\ \text { \% STUDIES } \\ \text { 1969 - 1979 }\end{array} \\ \text { PURPose } & & 1980-1990 \\ \text { Descriplive } & 80,0 & 78,1 \\ \text { Evaluative } & 5,6 & 7,7 \\ \text { Explanatory } & 3,7 & 5,1 \\ \text { Methodological } & 1,9 & 2,6 \\ \text { Theory testing } & - & 2,6 \\ \text { Theory development } & - & 1,3 \\ \text { Presentation of } & & \\ \text { literature finding } & 13,0 & 2,6\end{array}$


- There is a dearth of indepth studies, and studies focusing on theory, development and theory testing.

- The majority of studies tend to be somewhat superficial, and at times shoddy.

- Samples used for descriptive surveys are very small and thus reduce the contribution of the study to the growing body of knowledge.

- In many cases designs are not the most appropriate for the stated purpose.

- There is almost a complete absence of conceptual or theoretical frameworks. If present, they are frequently incorrectly used.

- Many unjustified generalisations occur.

- Statements and decisions are rarely substantiated, and many results are inconclusive.

- Results are seldom related to earlier findings.

- Though the research can be categorised in areas, within each area a shotgun approach is manifested and there is as yet no discernible body of focused nursing research.

Given these characteristics, nursing research in South Africa can be described as being in the toddler stage. Like a toddler it is heading off in all directions at once and influenced by immediate concerns rather than long term consideration. On the other hand in spite of many methodological defects, a considerable number of studies have served a very useful purpose for the improvement of nursing education, nursing practice and the profession as a whole (Searle, 1990).

\section{ISSUES AND EVENTS WHICH HAVE INFLUENCED THE STATUS OF NURSING RESEARCH}

\section{The Educational System}

It is generally recognised that the development of nursing research depends among others on the availability of experts (Bums and Grove 1987; Bergman 1990; Kelly 1991; Polit and Hungler 1991). The development of research is thus closely allied to the education system of the country.

Prior to 1956 all basic nursing education in South Africa was hospital-based. The only nursing programme offered at a university was a one-year post-registration diploma course for nurse educators. Preparation for the inculcation of research attitudes and guidance in research principles and methodology were absent from both basic and post-registration courses. The first basic nursing degree was introduced in 1956. It took two decades to establish basic nursing degree programmes in the rest of South African universities. During this period a lack of nursing faculty who were prepared in nursing research hampered the development of the research component for these degree programmes. Post-graduate nursing programmes were established in 1967 and as already mentioned the first group of nurses graduated from the masters programme in 1969. Since the mid-eighties the research component in the curriculum is a compulsory requirement for all basic and post-basic degree and diploma programmes in the country. By 1990 there were fourteen university departments offering basic nursing education degrees and twenty-eight nursing colleges offering diploma courses for registration as a nurse (general, community and psychiatric) and midwife. Twelve university nursing departments offer post-registration and post-graduate degrees.

The pool of nurses with advanced research preparation, though increasing is still small in comparison to the total registered nurse population. In 1990 the South African Nursing Council reported a total of 66146 registered nurses in South Africa. The number of nurses prepared at masters level was 262 (less than $0,4 \%$ of the total registered nurse population) while the number of earned doctorates was 49 (less than $0,07 \%$ ). The total number of nurses with a formal advanced preparation in research (masters and doctoral level) was 311 (less than $0,5 \%$ of the total). There is thus still an insufficient number of nurses prepared at an advanced level in research to provide guidance and mentoring to students. It is particularly the clinical areas and diploma courses which are hard hit, that nurses whose own research experience is limited are expected to assume research responsibilities.

\section{A vailable Funding}

Research as we all know is expensive. Most nurses undertaking research are therefore dependent on financial assistance. Before the 1980 s financial assistance for nurse researchers was virtually non-existent. The first nurse in South Africa to obtain a masters degree and subsequently a doctoral degree in 1951 and 1964 respectively was unable to obtain any form of financial support for her research as all the authorities who were approached were unable to accept that a nurse could do quality research (Searle 1990: 187). Gradually attitudes changed and since the early eighties increasing numbers of nurses have been assisted financially. Research funding is now available from several sources:

\section{The Medical Research Council}

Funds from this body are allocated mainly to biomedical research and as far as is known, no nurse has yet been funded by this body.

\section{Q The Human Sciences Research Council}

Since the early eighties a number of nurses have been funded for masters and doctoral research. In 1984, a nurse was appointed as a member of the assessment panel for research grants made available to nurses by this body.

\section{University Research Funds}

These are limited to staff members of the university, and awarded according to merit.

\section{The South African Nursing Association}

The Association established a National Research fund in 1983 and has since assisted a number of nurses with small grants. In 1987 this association introduced a post-masters bursary which is awarded every third year to one person for independent nursing research. Considered within the national context funding is still limited for nurse researchers. This is a powerful inhibiting factor to the progress of research in the 1990s.

\section{Infrastructure}

Until the eighties resources such as computer facilities, research and clinical consultants, easy access to libraries, research publications and formal structurers for the conduct of research were very scarce, if at all available. This is gradually improving. Faculty and students at universities have reasonable access to such resources and facilities but nurses in clinical areas experience problems.

Since 1983 the South African Nursing Association has made a concerted effort towards the development of nursing research in the country. During 1983 a nursing research unit was established and as already mentioned, a National Nursing Research Fund. A research post was instituted. Research priorities were determined at national level and a research nursing plan was developed. The library was expanded and nurse researchers are encouraged to deposit copies of research studies in the library.

Since 1984 one volume of the National Nursing Research Register has been published annually. The first volume indexed all studies done between 1951 and 1984. Successive volumes indexed all studies done in that particular year. To date eight such volumes are available to nurse researchers.

By 1990 no computer facilities nor research and statistical consultants had been added to the research structure of the South African Nursing Association.

At present no Nursing Research Centres have been instituted in either universities or health care institutions. As far as could be established, at one university an institute for nursing research has been set up.

No posts for independent nurse researchers or full-time nurse research consultants are available in any of the staffing establishments of higher education sectors, hospitals and other health care agencies or research councils. Although $90 \%$ of doctorally 
prepared nurses are in university posts, they have to fulfil a variety of roles, so that little time is left for research.

Access to facilities, particularly clinical facilities which permit clinical research is still problematic. Permission is rarely granted. Nurse researchers are looked upon as nuisances by several nursing authorities. There is an overall lack of institutional support for nurse researchers.

\section{Communication and Collaboration} Structure

\section{Journals}

Prior to 1978 no medium for the publication of completed research studies existed. Research completed had either to be published in book form or in pamphlet or bound, typed copy forms (Searle 1990: 188). This restricted the distribution of South African nursing research.

In 1978 Curationis, a journal devoted to nursing research and professional matters came into existence. Eight years later in 1986 less than $5 \%$ of articles published in this journal were research studies. In 1986 Curationis was subtitled "The Research Journal of the S.A. Nursing Association" and designated for the publication of substantial research studies and scholarly articles. From 1986 to 1990 a total of eighty research studies appeared in this journal. To date its circulation is still under 1000 and its viability is threatened.

\section{Conferences}

Annual nursing research conferences have been held since 1985 . The first three conferences were sponsored by a host university on a volunteer basis, but since 1988 , the National Society for nurse researchers has taken over. Interest in these conferences is very low and on the whole they are poorly attented.

\section{Intra-disciplinary Collaboration}

There is little evidence of collaboration among nurse researchers. University based nurses rarely involve practising nurses in their research or even colleagues from other universities or their own. Mostly each nurse who conducts research conducts shotgun research in isolation. No programmes of research have been established, with the exception of a programme to develop a theory of nursing in S.A. A small group of nurse leaders joined forces in 1989 to initiate this programme. As it is a closed group no further information is available.

\section{Inter-disciplinary Collaboration}

On the whole nurses are inclined to keep to themselves and do their research in isolation, rather than seek the expertise of the older disciplines which are inclined to view nursing research with much scepticism. In recent years a handful of nurses have become involved in projects with epidemiologists and oncologists. This can be considered as very positive.

\section{International Communication}

For decades access to intemational bodies and international research literature has been virtually impussible for South African nurses, due to international sanctions and boycotts. South African nurses were excluded from International Research conferences and forums and therefore had no means to be on the cutting edge of nursing research. This is changing and since 1990 nurse researchers have begun to enter into collaborative research with international colleagues, particularly in the transcultural field.

\section{Establishment of the National Society of Nurse Researchers}

A noteworthy landmark in the development of nursing research was the establishment of the Society of Nurse Researchers in 1987. This society functions under the auspices of the South African Nursing Association and with close on forty members aims to promote nursing research in South Africa. Since 1989 it has offered mentors courses, workshops and a consultation service for members and other interested parties, and organised annual research conferences.

\section{CONCLUSION}

Despite the fact that nursing research in South Africa is still in the toddler phase and has a long way to go, the future shows great promise if the progress of the past years is maintained, intra- and inter-disciplinary communication and collaboration improves and international colleagues remain committed to share their expertise.

\section{REFERENCES}

BERGMAN, R (ed). 1990. Nursing research for nursing practice: An international perspective. London: Chapman and Hall.

BURNS, N. \& GROVE, S.K. 1987. The practice of nursing research. Philadelphia: W.B. Saunders.

CURATIONIS - The Research Journal of the S.A. Nursing Association. 1986-1990. Vols. 9-13.

CURATIONIS - The South African Journal of Nursing. 1978-1985. Vols. 1-8.

KELLY, L.Y. 1991. Dimensions of professional nursing. New York: Pergamon Press.

POLIT, D.F. \& HUNGLER, B.P. 1991. Nursing research, principles and methods. 4th edition. Philadelphia: Lippincott.

S.A. NURSING ASSOCIATION. 1984 to 1990. National Nursing Research Register. Vols. 1-7. Pretoria.

S.A. NURSING COUNCIL. Statistical returns for the calendar year 1990 . Pretoria.

SEARLE, C. 1990. Research as a modifier of the constraints in developing nursing practice in South Africa: An overview in Nursing Research for Nursing Practice: An international perspective. (ed. R Bergman) London: Chapman \& Hall

UYS, H.H.M. \& BASSON A. 1991. Navorsingsmetodologie in die verpleegkunde. Pretoria: HAUM.

UYS, L.R. 1982. Nagraadse verpleegkunde navorsing aan Suid-Afrikaanse universiteite. 1969-1979. Curationis S(no. 1): 26-34.

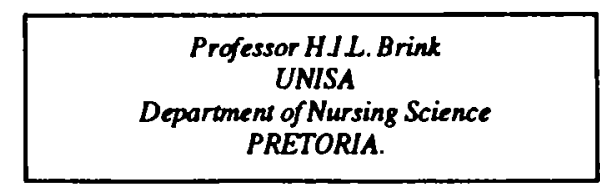

